\title{
An Opponent Process Approach to Modeling the Blue Shift of the Human Color Vision System
}

\author{
Brian A. Barsky, Todd J. Kosloff, and Steven D. Upstill ${ }^{1}$ \\ Computer Science Division, University of California, Berkeley, California, 94720-1776, U.S.A.
}

\section{Introduction}

Low light level affects human visual perception in various ways. Visual acuity is reduced and scenes appear bluer, darker, less saturated, and with reduced contrast. We confine our attention to an approach to modeling the appearance of the bluish cast in dim light, which is known as blue shift. Both photographs and computer-generated images of night scenes can be made to appear more realistic by understanding these phenomena as well as how they are produced by the retina.

The retina comprises two kinds of photoreceptors, called rods and cones. The rods are more sensitive in dim light than are the cones. Although there are three different kinds of cones with different spectral sensitivity curves, all rods have the same spectral response curve. Consequently, rods provide luminance information but no color discrimination. Thus, when the light is too dim to fully excite the cones, scenes appear desaturated. The opponent process theory of color vision [Hurvich and Jameson 1957] states that the outputs of the rods and cones are encoded as red-green, yellow-blue, and white-black opponent channels. We model loss of saturation and blue shift in this opponent color space.

\section{Previous Work}

In 1985, we produced a comprehensive computational model which, among many other things, takes into account the perceived color at low levels of illumination [Upstill 1985]. This component of our model processes images to appear as if they were viewed at night by desaturating and blue-shifting the image. Here, we improve on our earlier model by calibrating it using psychophysical data from [Hunt 1952].

Recently, Thompson et al. presented a technique which, like ours, produces night images by taking into account desaturation and blue shift [Thompson 2002]. Also like us, they used Hunt's psychophysical data to calibrate their blue shift. However, they transformed colors using an ad-hoc set of equations, whereas our formulation derives from physiological knowledge of the human visual system [Hurvich and Jameson 1957].

\section{Method}

The purpose of our work is to apply Hunt's blue-shift data to our own model, which differs from Thompson's in that it works in a biologically inspired color space where the two color channels represent opponent colors: a yellow-blue color channel and a redgreen color channel.

Copyright $\odot 2004$ by the Association for Computing Machinery, Inc.

Permission to make digital or hard copies of part or all of this work for personal or classroom use is granted without fee provided that copies are not made or distributed for commercial advantage and that copies bear this notice and the full citation on the first page. Copyrights for components of this work owned by others than ACM must be honored. Abstracting with credit is permitted. To copy otherwise, to republish, to post on servers, or to redistribute to lists, requires prior specific permission and/or a fee Request permissions from Permissions Dept, ACM Inc., fax +1 (212) 869-0481 or e-mail permissions@acm.org.

(c) 2004 ACM 1-58113-914-4/04/0008 $\$ 5.00$
Once in the opponent color space, our method shifts the yellowblue channel into the blue direction while simultaneously scaling down both color channels to produce desaturation. We use psychophysical data from [Hunt 1952] to match our "blue shift" results with what is experimentally observed. Our blue shift model as published in [Upstill 1985] contained manually controlled parameters; here, we replace those constants with psychophysically valid values.

\section{Results}

Figures 1 and 2 show examples of images before and after processing by our blue shift model. In Figure 1, a photograph of a real scene is used and Figure 2 is based on a computer-generated image.
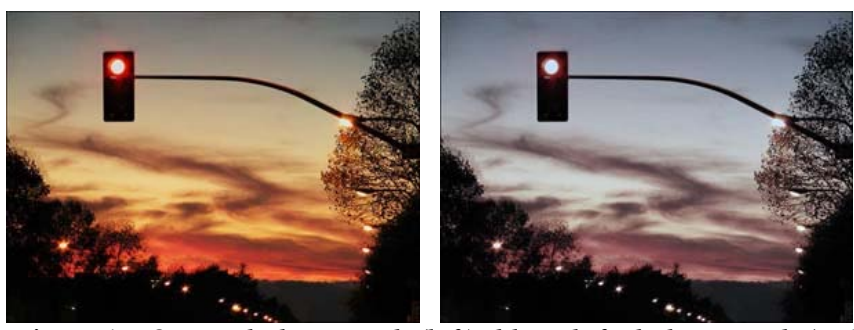

Figure 1: Original photograph (left); blue-shifted photograph (right).
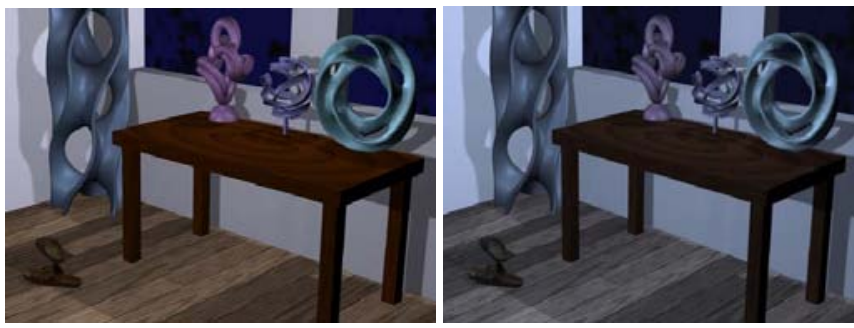

Figure 2: Computer generated image (left); blue-shifted image (right).

\section{References}

Thompson, William B., Shirley, Peter, and Ferwerda, James A. A spatial post-processing algorithm for images of night scenes. Journal of Graphics Tools, Vol. 1, No. 1, 2002, pp. 1-12.

Hunt, Robert W.G. Light and dark adaptation and the perception of color. Journal of the Optical Society of America, Vol. 42, No. 3, March 1952, pp. 190-199.

Hurvich, Leo and Jameson, Dorthea. An opponent-process theory of color vision. Psychological Review, Vol. 64, pp. 384-390, 1957.

Upstill, Steven D. The Realistic Presentation of Synthetic Images: Image Processing in Computer Graphics. Ph.D. thesis, University of California, Berkeley, 1985.

\footnotetext{
${ }^{1}$ Box Rocket Animation Ltd. Wellington, New Zealand
} 